\title{
Pengaruh Belajar Tipe Teams Games Tournament (TGT) Terhadap Hasil Belajar Matematika
}

\author{
${ }^{1}$ Anas Taufiqurrahman, ${ }^{2}$ Andes Safarandes Asmara, M.Pd \\ 1, 2Pendidikan Guru Sekolah Dasar (PGSD), FKIP Universitas Buana Perjuangan, INDONESIA \\ e-mail: ${ }^{1}$ sd16.anastaufiqurrahman@mhs.ubpkarawang.ac.id, 2andes@ubpkarawang.ac.id
}

\section{The Effect of Teams Games Tournament (TGT) Learning Type on Mathematics Learning Results}

\section{Kata Kunci}

Tipe TGT, Hasil Belajar Matematika

\begin{abstract}
Abstrak
Penelitian ini bertujuan untuk mengetahui pengaruh metode pembelajaran kooperatif tipe Teams Games Tournament (TGT) terhadap hasil belajar Matematika di SD Negeri Adiarsa Barat II, Kecamatan Karawang Barat, Kabupaten Karawang. Penelitian ini merupakan jenis penelitian kuantitatif. Populasi pada penelitian ini yaitu peserta didik kelas II SD Negeri Adiarsa Barat II. Sampel pada penelitian berjumlah 22 . Teknik pengumpulan data melalui tes isian dengan mata pelajaran Matematika. Peneliti menggunakan teknik analisis data yaitu perhitungan statistik. Hasil pengujian hipotesis, terdapat perbedaan yang signifikan antara metode pembelajaran kooperatif tipe Teams Games Tournament (TGT) dengan hasil belajar Matematika. Hal ini diperoleh ( $\left.t_{\text {hitung }}=5.813>t_{\text {tabel }}=2,085\right)$ dengan signifikansi 0,05 dan $n=22$ menunjukan bahwa hipotesis diterima. Dari hasil penelitian ini bisa dikatakan ada perbedaan hasil belajar Matematika dengan metode pembelajaran kooperatif tipe Teams Games Tournament (TGT).
\end{abstract}

Abstract:
This study aims to determine the effect of the Teams Games
Tournament (TGT) type of cooperative learning methods on
mathematics learning outcomes at Adiarsa Barat II Elementary School,
West Karawang District, Karawang District. This research is a type of
quantitative research. The population in this study were grade II
students of Adiarsa Barat II Elementary School. The sample in this study
amounted to 22 . The technique of collecting data through filling tests
with Mathematics subjects. Researchers use data analysis techniques,
namely statistical calculations. The results of hypothesis testing, there
are significant differences between the cooperative learning methods of
Teams Games Tournament (TGT) and Mathematics learning outcomes.
This was obtained (tcount = 5.813> t table = 2.085) with a significance
of 0.05 and $n=22$ indicating that the hypothesis was accepted. From
the results of this study it can be said there are differences in learning
outcomes in Mathematics with cooperative learning methods of the
Teams Games Tournament (TGT) type
Article History:
Received: 5 Januari 2019
Revised: 6 Februari 2019
Accepted: 10 Mei 2019

Keywords:

TGT Type, Mathematics Learning Outcomes 


\section{Pendahuluan}

Pendidikan Sekolah Dasar (SD) merupakan jenjang dasar, pondasi bagi peserta didik dalam pendidikan di Sekolah Dasar membangun dasar pengetahuan peserta didik untuk digunakan pada pendidikan selanjutnya, oleh karena itu pembelajaran di sekolah harus berjalan optimal. Sehingga pendidikan merupakan proses suatu pembelajaran pengetahuan yang dilakukan sesorang untuk mendapatkan suatu ilmu yang berguna. Sedangkan menurut UU No. 20 Tahun 2003 menjelaskan bahwa pendidikan adalah usaha sadar dan terencana untuk mewujudkan suasana belajar dan proses pembelajaran agar peserta didik secara aktif mengembangkan potensi dirinya untuk memiliki kekuatan spiritual keagamaan, pengendalian diri, kepribadian, kecerdasan, akhlak mulia, serta keterampilan yang diperlukan dirinya, masyarakat, bangsa dan Negara.

Dalam pendidikan, siswa diharuskan untuk belajar, belajar merupakan sesuatu hal yang biasa orang lakukan, untuk mendapatkan ilmu yang lebih banyak, untuk itulah belajar sangat pentung. Karena itu dapat menumbuh kembangkan kecerdasan manusia. Seperti halnya peserta didik SD yang melakukan kegiatan belajar di Sekolah, dari awal masuk sekolah dengan belajar peserta didik akan menjadi tahu hal yang belum diketahui menjadi tahu. Seperti yang dikemukakan (M. Sobry Sutikno, Sudjana, Suprijono) pengertian belajar adalah suatu proses usaha yang dilakukan oleh seseorang untuk mendapatkan suatu perubahan yang baru sebagai hasil pengalamannya sendiri dalam interaksi dengan lingkungannya. Dalam hal ini, perubahan adalah sesuatu yang dilakukan secara sadar (disengaja) dan bertujuan untuk memperoleh suatu yang lebih baik dari sebelumnya. Dengan belajar potensi yang ada dalam diri setiap peserta didik dapat berkembang. Keberhasilan peserta didik dalam belajar didukung beberapa faktor diantaranya faktor dari dalam dan faktor dari luar. Faktor dari dalam seperti kecerdasan, minat, motivasi, kemampuan kognitif dan lainnya. Sedangkan faktor dari luar seperti lingkungan keluarga, lingkungan sekolah dan lingkungan masyarakat.

Salah satu hasil belajar yang rendah yang biasanya diperoleh peserta didik sekolah dasar yaitu pada mata pelajaran matematika. Peserta didik menganggap bahwa matematika sulit sehingga merasa takut dan malas untuk mempelajari. Pembelajaran matematika yang melatih peserta didik dalam menjumlah satuan hingga ratusan adalah kemampuan dalam menyelesaikan soal berhitung menyimpan. Pembelajaran matematika adalah proses pemberian pengalaman belajar kepada peserta didik melalui serangkaian kegiatan yang terencana sehingga peserta didik memperoleh pengetahuan tentang matematika yang dipelajari, cerdas, terampil, mampu memahami dengan baik bahan yang diajarkan Amir, (2014).

Berdasarkan observasi pendahuluan yang dilakukan pada tanggal 8 November 2018, proses pembelajaran di SD Negeri Adiarsa Barat II dalam proses pembelajaran guru masih menggunakan metode ceramah, kurangnya antusias peserta didik dalam mengikuti proses pembelajaran matematika, sehingga pembelajaran lebih terpusat pada guru sehingga keaktifan belajar siswa masih rendah, pemahaman konsep peserta didik pada mata pelajaran matematika masih dibawah KKM, guru belum menerapkan metode pembelajaran yang inovatif dalam pembelajaran seperti yang terjadi di SD Negeri Adiarsa Barat II.

Kondisi tersebut perlu untuk penerapan metode pembelajaran yang bervariasi agar peserta didik dapat mengembangkan kemampuan untuk percaya diri dan pemahaman konsep tentang materi matematika. Pembelajaran tersebut salah satunya dapat diwujudkan melalui metode pembelajaran kooperatif tipe Teams Games Tournament (TGT). Metode pembelajaran TGT memberi kesempatan kepada peserta didik untuk membagikan ide-ide dan mempertimbangkan jawaban yang paling tepat. Metode pembelajaran kooperatif tipe Teams Games Tournament (TGT) adalah "metode pembelajaran kooperatif yang melibatkan aktivitas seluruh siswa tanpa adanya perbedaan status, melibatkan peran siswa sebagai tutor sebaya, dan mengandung unsur permainan dan reinforcement. Aktivitas siswa dengan metode Teams Games Tournament (TGT) memungkinkan siswa dapat belajar lebih rileks disamping 
menumbuhkan tanggung jawab, kerja sama, persaingan sehat dan keterlibatan belajar" Hamdani, (2011). Menurut Huda (2011: 116) mengemukakan bahwa penerapan TGT mirip dengan STAD dalam hal komposisi kelompok, format instruksional, dan lembar kerjanya. Bedanya jika STAD fokus pada komposisi kelompok berdasarkan kemampuan, ras, etnik, dan gender, maka TGT umumnya fokus hanya pada level kemampuan saja. Sedangkan menurut Trianto (2010: 83) menambahkan bahwa pada model TGT siswa dibagi menjadi 17 beberapa kelompok yang terdiri dari 3 - 5 orang untuk memainkan permainan dengan anggota-anggota tim lain untuk memperoleh

Melalui metode pembelajaran kooperatif tipe TGT diharapkan peserta didik dalam hasil belajar matematika dapat meningkat. Hal ini dikarenakan metode pembelajaran kooperatif tipe TGT dapat menjadikan peserta didik lebih aktif, dapat bekerja sama dengan teman sekelompoknya, peserta didik menjadi percaya diri, dapat mengembangkan keterampilan peserta didik, dengan demikian pemahaman peserta didik akan lebih meningkat.

\section{Metode Penelitian}

a. Tempat dan Waktu Penelitian

Penelitian ini dilaksanakan di SD Negeri Adiarsa Barat II, Kecamatan Karawang Barat, dan penelitian ini difokuskan pada peserta didik kelas II SD Negeri Adiarsa Barat II. Tahun Ajaran 2018/2019. Waktu penelitian ini dilaksanakan pada semester genap tahun 2018/2019, dimulai pada bulan November 2018.

\section{b. Desain dan Metode Penelitian}

Penelitian ini menggunakan pendekatan kuantitatif dengan metode eksperimen. Metode eksperimen yaitu metode yang menjadikan bagian dari metode kuantitatif dan mempunyai ciri khas tersendiri, yaitu dengan adanya kelompok kontrolnya. Menurut Sugiyono (2017, hlm. 72) metode penelitian eksperimen dapat diartikan sebagai metode penelitian yang digunakan untuk mencari pengaruh perlakuan tertentu terhadap yang lain dalam kondisi yang terkendalikan.

Penelitian ini termasuk jenis True Experimental Design dengan menggunakan PretestPosttest Control Group Design. Design ini memiliki dua kelompok yang dipilih secara random, kemudian diberi pretest untuk dapat mengetahui keadaan awal apakah ada perbedaan antara kelompok eksperimen dan kelompok kontrol. Adapun pola desain penelitian ini sebegai berikut:

Tabel 1. Desain Penelitian

\begin{tabular}{|c|c|c|c|}
\hline & Pre-test & Treatment & Post-test \\
\hline $\mathrm{KE}$ & $\mathrm{O}_{1}$ & $\mathrm{X}$ & $\mathrm{O}_{2}$ \\
\hline $\mathrm{KO}$ & $\mathrm{O}_{3}$ & - & $\mathrm{O}_{4}$ \\
\hline
\end{tabular}

Keterangan :
KE : Kelompok Eksperimen
KO : Kelompok Kontrol
$\mathrm{O}_{1} \quad$ : Pre-test kelompok eksperimen
$\mathrm{O}_{2} \quad$ : Post-test kelompok eksperimen
$\mathrm{O}_{3} \quad$ : Pre-test kelompok kontrol
$\mathrm{O}_{4} \quad$ : Post-test kelompok kontrol
$\mathrm{X} \quad$ : Perlakuan pada kelompok eksperimen menggunakan metode pembelajaran 


\section{Teams Games Tournament (TGT)}

c. Sampel Penelitian

Pada penelitian ini akan digunakan sampel penelitian. Sampel adalah bagian dari jumlah dan karakteristik yang hanya dimiliki oleh populasi tersebut. Sampel dalam penelitian ini adalah peserta didik kelas II yang terdiri dari 22 siswa di SDN Adiarsa Barat II Tahun Pelajaran 2018/2019.

Adapun jumlah peserta didik pada tabel berikut ini.

Tabel 2. Jumlah Sampel Penelitian

\begin{tabular}{|l|c|c|c|c|}
\hline \multicolumn{1}{|c|}{ Kelompok } & Kelas & Laki-laki & Perempuan & Jumlah Peserta didik \\
\hline Eksperimen & II & 10 & 12 & 22 \\
\hline Kontrol & II & 10 & 12 & 22 \\
\hline
\end{tabular}

\section{d. Teknik Pengumpulan Data}

Teknik pengumpulan data yang digunakan dalam penelitian ini adalah tes. Tes digunakan untuk mengukur hasil belajar matematika yaitu berupa soal isian 30 butir, yang akan digunakan pada pretest dan post-test. Pretest digunakan untuk mengukur kemampuan peserta didik sebelum diberi perlakuan. Post-test digunakan untuk mengukur kemampuan peserta didik setelah diberi perlakuan. Setelah diadakan pretest dan post-test kemudian hasil kedua tes tersebut dibandingkan. Apakah ada perbedaan antara sebelum dan sesudah diberi perlakuan.

\section{Hasil dan Pembahasan}

Pengujian hipotesis dilakukan untuk mengetahui apakah ada perbedaan rata-rata data akhir hasil belajar Matematika kelompok eksperimen dan kelompok kontrol. Dalam uji data Independent samples $t$-test ini peneliti menggunakan bantuan program SPSS v.16. Adapun hipotesis dalam penelitian adalah sebagai berikut:

$\mathrm{H}_{\mathrm{o}} \quad: \mu_{1}=\mu_{2}$ : Jika tidak terdapat perbedaan hasil belajar Matematika menggunakan metode kooperatif tipe TGT yang tidak menggunakan metode kooperatif tipe TGT

$\mathrm{H}_{\mathrm{a}}: \mu_{1} \neq \mu_{2}$ : Jika terdapat perbedaan hasil belajar Matematika menggunakan metode kooperatif tipe TGT dan yang tidak menggunakan metode kooperatif tipe TGT

Jika nilai sig. (2-tailed) $<0,05$ maka $\mathrm{H}_{\mathrm{o}}$ ditolak dan $\mathrm{H}_{\mathrm{a}}$ diterima

Jika nilai sig. (2-tailed) >0,05 maka $\mathrm{H}_{\mathrm{a}}$ ditolak dan $\mathrm{H}_{\mathrm{o}}$ diterima.

Tabel 3. Uji Hipotesis Penelitian

Independent Samples Test

\begin{tabular}{|c|c|c|c|c|c|c|c|c|c|c|}
\hline & \multicolumn{2}{|c|}{\begin{tabular}{|c|} 
Levene's Test \\
for Equality \\
of Variances
\end{tabular}} & \multicolumn{7}{|c|}{ t-test for Equality of Means } \\
\hline & & \multirow[b]{2}{*}{$\mathrm{F}$} & \multirow[b]{2}{*}{ Sig. } & \multirow[b]{2}{*}{$\mathrm{t}$} & \multirow[b]{2}{*}{$\mathrm{df}$} & \multirow{2}{*}{$\begin{array}{l}\text { Sig. } \\
(2- \\
\text { taile } \\
\text { d) }\end{array}$} & \multirow{2}{*}{$\begin{array}{c}\text { Mean } \\
\text { Differenc } \\
\text { e }\end{array}$} & \multirow{2}{*}{$\begin{array}{l}\text { Std. } \\
\text { Error } \\
\text { Diffe } \\
\text { rence }\end{array}$} & \multicolumn{2}{|c|}{$\begin{array}{c}95 \% \\
\text { Confidence } \\
\text { Interval of } \\
\text { the } \\
\text { Difference }\end{array}$} \\
\hline & & & & & & & & & $\begin{array}{c}\text { Lowe } \\
r\end{array}$ & Upper \\
\hline Hasil Belajar & $\begin{array}{l}\text { Equal } \\
\text { variances } \\
\text { assumed }\end{array}$ & 1.038 & .314 & 5.813 & 42 & .000 & 8.000 & 1.376 & 5.223 & 10.777 \\
\hline
\end{tabular}

JSD : Jurnal Sekolah Dasar | 85 
Independent Samples Test

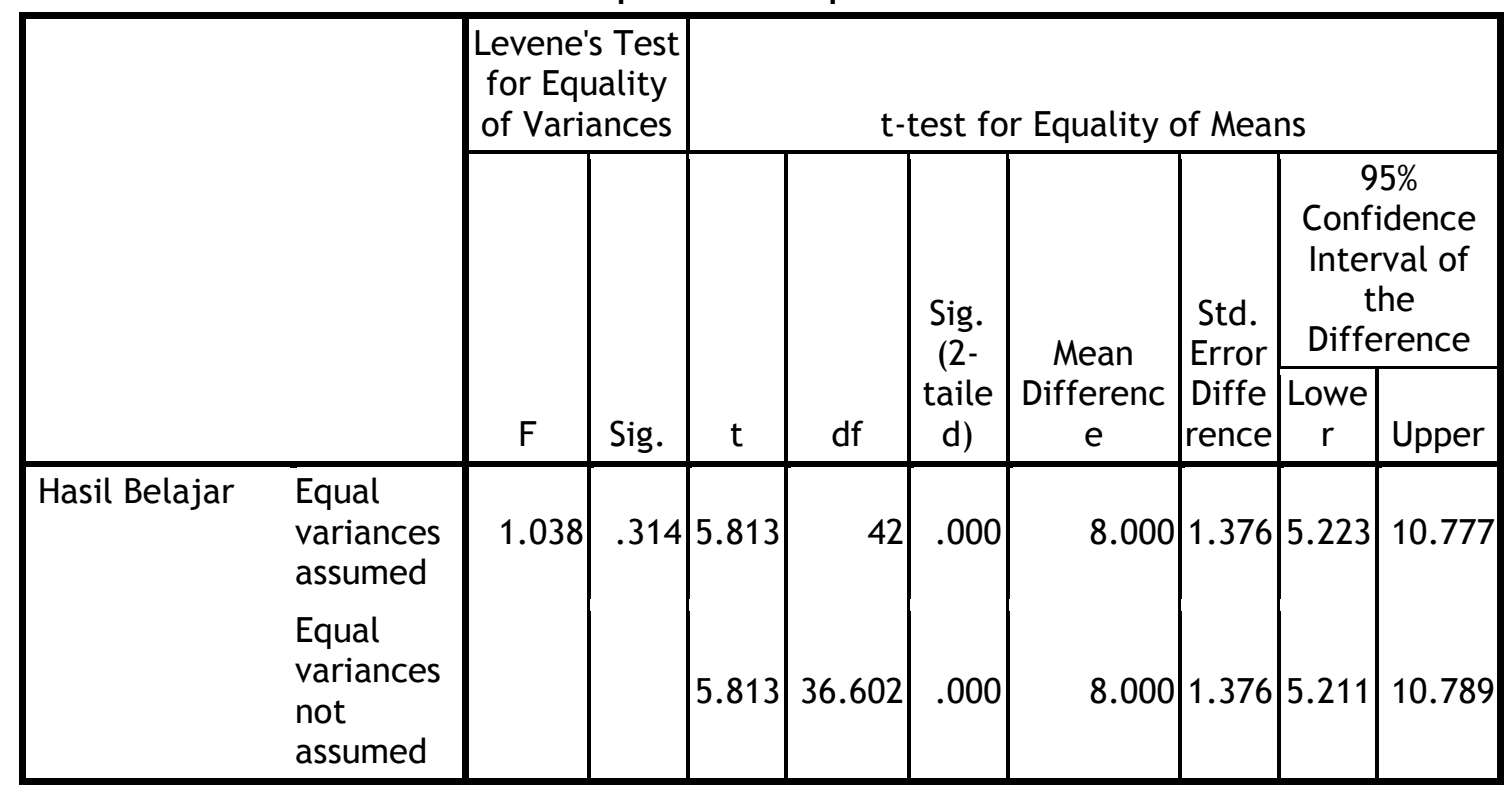

Berdasarkan hasil uji-t menunjukan bahwa adanya pengaruh pembelajaran menggunakan metode kooperatif tipe TGT terhadap hasil belajar Matematika. Hal ini sesuai dengan perhitungan program SPSS versi 16 yang dengan analisis uji-t yang menggunakan taraf signifikan 0,05 . Hasil perhitungan data menunjukan bahwa nilai sig $=0,00<0,05$. Dari proses perhitungan hasil nilai $\mathrm{t}$ - hitung sebesar 5.813 dan nilai t-tabel 2,085. Dari perbandingan antara $\mathrm{t}$-hitung lebih besar dari $\mathrm{t}$-tabel $\left(\mathrm{t}_{\text {hitung }}=5.813>\mathrm{t}_{\text {tabel }}=2,085\right)$. Dengan demikian $\mathrm{H}_{\mathrm{a}}$ diterima dan $\mathrm{H}_{0}$ ditolak, maka dapat disimpulkan bahwa terdapat perbedaan hasil belajar matematika yang menggunakan metode kooperatif tipe TGT dengan hasil belajar Maematika yang tidak menggunakan metode kooperatif tipe TGT.

Hal ini menunjukkan hasil belajar siswa meningkat. Menurut Andayani, (2015) menyatakan bahwa "indikator keberhasilan pembelajaran terwujud apabila siswa sejahtera dalam belajar, untuk itu maka perlu disajikan sebuah aktivitas belajar murid yang bervariasi atau beraham cara, sehingga dapat menyenangkan dan menggairahkan terutama bagi murid". Dengan menerapkan metode pembelajaran Teams Games Tournament (TGT) dalam pembelajaran membaca permulaan dapat memudahkan siswa dalam belajar karena mereka merasa nyaman belajar kelompok dengan teman-temannya dan dapat meningkatkan gairah belajar karena mereka akan berlomba-lomba dalam menjawab pertanyaan guru untuk memenangkan permainan.

Berdasarkan hasil di atas, metode kooperatif tipe TGT berpengaruh terhadap peserta didik dalam bekerjasama untuk mengerjakan soal dalam proses belajar, Sehingga pemahaman peserta didik yang diberikan treatment lebih baik dibandingkan pada pemahaman yang tidak diberikan treatment. Setelah dilakukan pembelajaran dengan yang diberikan treatment dan yang tidak diberikan treatment, maka hasil belajar Matematika tersebut dapat dibandingkan dan di uji beda antara pretest dan posttest untuk melihat apakah ada perbedaan dengan penerapan metode kooperatif tipe TGT.

\section{Kesimpulan}

Dapat disimpulkan, hasil dari penelitian pengaruh belajar tipe teams games tournament (TGT) dapat berpengaruh terhadap hasil belajar matematika di kelas II SD Negeri Adiarsa Barat II. Hasil tersebut diperoleh dengan menggunakan aplikasi SPSS versi 16 dengan nilai sig $=0,00<0,05$. Dari proses perhitungan hasil nilai $\mathrm{t}$ - hitung sebesar 5.813 dan nilai $\mathrm{t}$ tabel 2,085. Dari perbandingan antara $\mathrm{t}$-hitung lebih besar dari $\mathrm{t}$-tabel $\left(\mathrm{t}_{\text {hitung }}=5.813>\mathrm{t}_{\text {tabel }}=\right.$ 2,085). Dengan demikian $\mathrm{H}_{\mathrm{a}}$ diterima dan $\mathrm{H}_{0}$ ditolak, maka dapat disimpulkan bahwa terdapat 
The Effect of Teams Games Tournament (TGT) Learning Type on Mathematics Learning Results

perbedaan hasil belajar Maematika yang menggunakan metode kooperatif tipe TGT dengan hasil belajar Maematika yang tidak menggunakan metode kooperatif tipe TGT.

\section{Daftar Pustaka}

Andayani. (2015). Problema dan Aksioma: Dalam Metodologi Pembelajaran Bahasa Indonesia (1st ed.). Jogyakarta: Deepublish.

Amir, A. (2014). Kemampuan Penalaran dan Komunikasi dalam Pembelajaran

Depdiknas. (2003). Undang-undang RI No.20 tahun 2003.tentang sistem pendidikan nasional

Hamdani. (2011). Strategi Belajar Mengajar. Bandung: CV Pustaka Setia.

Huda, Miftahul. (2011). Cooperative Learning. (Yogyakarta: Pustaka Belajar)

M. Sobry Sutikno, (2010). Belajar dan Pembelajaran, Prospect. Bandung, 2010

Sudjana. Dasar-dasar Proses Belajar Mengajar (Bandung: Sinar Baru Algasindo)

Sugiyono. (2017). Metode Penelitian Kuantitatif, Kualitatif, dan R\&D. Bandung: Alfabeta

Suprijono. (2010). Cooperative Learning (Yogyakarta : Pustaka Pelajar)

Trianto. 2010. Model Pembelajaran Terpadu, Konsep, Strategi dan Implementasinya dalam KTSP. Jakarta: Bumi Aksara. 